\title{
High but stable incidence of adult-onset asthma in northern Sweden over the last decades
}

\author{
Petri Räisänen ${ }^{1}$, Helena Backman $\mathbb{D}^{1,2}$, Linnea Hedman ${ }^{1,2}$, Martin Andersson ${ }^{1}$, Caroline Stridsman $\mathbb{B}^{3}$, \\ Hannu Kankaanranta ${ }^{4,5,6}$, Pinja Ilmarinen $\mathbb{1}^{5,6}$, Heidi Andersen $\mathbb{C}^{5}$, Päivi Piirilä ${ }^{7}$, Anne Lindberg $^{3}$, \\ Bo Lundbäck ${ }^{4}$ and Eva Rönmark $\mathbb{Q}^{1}$
}

${ }^{1}$ Dept of Public Health and Clinical Medicine, Section of Sustainable Health, the OLIN unit, Umeå University, Umeå, Sweden. ${ }^{2}$ Dept of Health Sciences, Luleå University of Technology, Luleå, Sweden. ${ }^{3}$ Dept of Public Health and Clinical Medicine, Section of Medicine, the OLIN unit, Umeå University, Umeå, Sweden. ${ }^{4}$ Krefting Research Centre, Institute of Medicine, University of Gothenburg, Gothenburg, Sweden. ${ }^{5}$ Faculty of Medicine and Health Technology, Tampere University, Tampere, Finland. ${ }^{6}$ Dept of Respiratory Medicine, Seinäjoki Central Hospital, Seinäjoki, Finland. ${ }^{7}$ Unit of Clinical Physiology, HUS Medical Diagnostic Center, Helsinki University Central Hospital and University of Helsinki, Helsinki, Finland.

Corresponding author: Eva Rönmark (eva.ronmark@norrbotten.se)

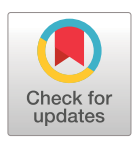

Copyright @The authors 2021

This version is distributed under the terms of the Creative Commons Attribution Non-Commercial Licence 4.0. For commercial reproduction rights and permissions contact permissions@ersnet.org

This article has supplementary material available from openres.ersjournals.com

Received: 27 May 2021 Accepted: 27 May 2021

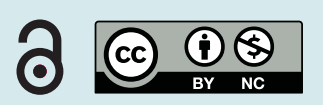

Shareable abstract (@ERSpublications)

The incidence of adult-onset asthma in adults has been stable in Sweden over the last 30 years but the relatively high incidence rate in combination with low remission rate in adulthood contributes to the reported increase in asthma prevalence among adults https://bit.ly/2QPOAF4

Cite this article as: Räisänen P, Backman H, Hedman L, et al. High but stable incidence of adult-onset asthma in northern Sweden over the last decades. ERJ Open Res 2021; 7: 00262-2021 [DOI: 10.1183/ 23120541.00262-2021].

\section{Abstract}

Background The prevalence of asthma has increased both among children and adults during the latter half of the 20th century. The prevalence among adults is affected by the incidence of asthma not only in childhood but also in adulthood. Time trends in asthma incidence have been poorly studied.

Aims The aim of this study was to review the incidence of adult-onset asthma from 1996 to 2006 and 2006 to 2016 and compare the risk factor patterns.

Methods In the Obstructive Lung Disease in Northern Sweden (OLIN) studies, two randomly selected population-based samples in the 20-69-year age group participated in postal questionnaire surveys about asthma in 1996 ( $n=7104,85 \%)$ and $2006(n=6165,77 \%)$. A 10-year follow-up of the two cohorts with the same validated questionnaire was performed, and 5709 and 4552 responded, respectively. Different definitions of population at risk were used in the calculations of asthma incidence. The protocol followed a study performed between 1986 and 1996 in the same area.

Results The crude incidence rate of physician-diagnosed asthma was 4.4 per 1000 person-years (men 3.8, women 5.5) from 1996 to 2006, and 4.8 per 1000 person-years (men 3.7, women 6.2) from 2006 to 2016. When correcting for possible under-diagnosis at study entry, the incidence rate was 2.4 per 1000 personyears from 1996 to 2006 and 2.6 per 1000 person-years from 2006 to 2016. The incidence rates were similar across age groups. Allergic rhino-conjunctivitis was the main risk factor for incident asthma in both observation periods (risk ratio 2.4-2.6).

Conclusions The incidence of adult-onset asthma has been stable over the last two decades and has remained at a similar level since the 1980s. The high incidence contributes to the increase in asthma prevalence.

\section{Introduction}

The prevalence of asthma is frequently studied, and a consistent pattern of a worldwide increase during the latter half of the 20th century has been reported, although the increase may have levelled off in some areas $[1,2]$. The reason for the increase is unclear, but changes in lifestyle and environments and rapid urbanisation may have contributed [1, 3-5]. Prevalence is mainly a function of incidence and remission. In adulthood, asthma is regarded as a chronic disease due to low remission [6, 7]. The prevalence of asthma among adults is not only a result of the high incidence in childhood and adolescence [8-11] with persistence into adulthood, but is also due to the relatively high incidence in adulthood [4, 12-24]. 
However, incidence studies of adult-onset asthma are scarce, particularly longitudinal population-based studies.

Comparing incidence rates of asthma is complex as the results are highly sensitive to the age of the study population and the methods used. Reported incidence estimates vary substantially but are higher among children and teenagers, 10-30 per 1000 person-years [8-11, 20], than among adults, 0.2-5 per 1000 person-years [4, 12-24]. Results from retrospective [11, 13, 22, 24, 25] and register studies [13] tend to generate lower incidence rates than prospective studies [11-21, 25]. The definition of both the outcome and the population at risk significantly influences the incidence rate $[12,15,18,19]$, which highlights the importance of using the same methods and definitions to enable comparisons of results from different studies and over time. Three studies carried out in Sweden and neighbouring countries, of which one was in the same area as the current study, using identical methods, reported similar incidence rates of physician-diagnosed asthma among adults from the 1980s up until 2006 of 2-3 per 1000 person-years $[15,16,18]$, but it is unknown if the incidence has changed since. As the prevalence of asthma in adults has increased in Sweden over the last decades [2, 26], we hypothesised that the incidence of adult-onset asthma is still high or has even increased during the same period. Thus, the main aim of the current study was to estimate the incidence of adult-onset asthma during the period 1996 to 2016 by surveys of two cohorts each followed for 10 years, one from 1996 to 2006 and the other from 2006 to 2016. A further aim was to identify risk factors for adult-onset asthma.

\section{Materials and methods}

\section{Study population}

The study was performed within the Obstructive Lung Disease in Northern Sweden (OLIN) Studies. All surveys were approved by the Regional Ethical Review Board at Umeå University.

The present paper is based on two random population samples, each followed for 10 years. The first sample consists of participants from a postal questionnaire survey performed in 1996 of a general population sample aged 20-69 years ( $n=7104,85 \%$ response rate) [2]. This cohort was followed-up with the same questionnaire in 2006, when 5709 individuals participated (80\% response rate). The second sample was recruited in 2006 using identical methods ( $n=6165,77 \%$ response rate) [2], and followed-up in 2016 ( $n=4552,74 \%$ response rate). Individuals from these two cohorts that participated both at baseline and at the follow-up constitute the study populations in the current paper: $n=5709$ from the cohort recruited in 1996 and $n=4552$ from the cohort recruited in 2006 (table 1). The surveys were all performed during the same time period from January to May. We have previously published incidence rates of adult-onset asthma based on a cohort recruited in 1986 in similar age groups and in the same area, which was followed-up in 1992 [12] and 1996 [15]. The calculations of incidence in the current paper followed the same protocol as that used in these previous studies.

\section{Questionnaire}

The OLIN questionnaire was used in all surveys. It was originally developed from a British Medical Research Council questionnaire and has been validated against physiological variables [27]. It has been used in the OLIN studies since 1986 and frequently in other studies of asthma and respiratory diseases in Sweden and other countries [18, 19, 24, 26].

TABLE 1 Study population: invited and participated by sex in the two cohorts followed over 10 years

\begin{tabular}{|c|c|c|c|c|c|c|}
\hline & \multicolumn{3}{|c|}{ Cohort recruited in 1996} & \multicolumn{3}{|c|}{ Cohort recruited in 2006} \\
\hline & Women & Men & All & Women & Men & All \\
\hline Invited $\mathrm{n}$ & 3982 & 4351 & 8333 & 3843 & 4154 & 7997 \\
\hline Participated n (\%) & $\begin{array}{c}3471 \\
(87.2)\end{array}$ & $\begin{array}{c}3633 \\
(83.5)\end{array}$ & $\begin{array}{c}7104 \\
(85.3)\end{array}$ & $\begin{array}{c}3135 \\
(81.6)\end{array}$ & $\begin{array}{c}3030 \\
(72.9)\end{array}$ & $\begin{array}{c}6165 \\
(77.1)\end{array}$ \\
\hline \multicolumn{7}{|l|}{ Invited to follow-up } \\
\hline $2006 n$ & 3336 & 3438 & 6774 & & & \\
\hline $2016 n$ & & & & 3001 & 2817 & 5818 \\
\hline Participated both in 1996 and 2006 n & 2876 & 2833 & 5709 & & & \\
\hline Participated both in 2006 and $2016 \mathrm{n}$ & & & & 2389 & 2163 & 4552 \\
\hline$\%$ of participants & 82.9 & 78.8 & 80.4 & 76.2 & 71.4 & 73.8 \\
\hline
\end{tabular}




\section{Definitions}

The main outcome was physician-diagnosed asthma. The definitions for asthma and respiratory symptoms were based on the following questions:

1. Physician-diagnosed asthma: "Have you been diagnosed as having asthma by a physician?"

2. Ever asthma: "Have you ever had asthma?"

3. Asthma medication use: "Do you currently use asthma medicines (on a regular basis or as needed)?"

4. Family history of asthma: "Have any of your parents or siblings asthma, or have they had asthma?"

5. Recurrent wheeze: "Do you usually have wheezing or whistling in your chest when breathing?"

6. Attacks of shortness of breath (SOB): Affirmative answer to both "Do you presently have, or have had in the last 10 years, asthma symptoms (intermittent breathlessness or attacks of shortness of breath; the symptoms may exist simultaneously with or without cough or wheezing)" and "Have you had these problems within the last year?”

7. Allergic rhino-conjunctivitis: "Do you have or have you had allergic nose or eye problems (hay fever)?”

8. Smoking habits: Smoking habits were divided into nonsmokers, ex-smokers (quit smoking at least 12 months prior to the survey) and smokers (smoked during the 12 months preceding the survey).

Classification of socioeconomic status was based on main occupation and categorised into three groups: professionals, non-manual workers and manual workers according to classifications by Statistics Sweden.

\section{Statistical analyses}

The analyses were performed using the software IBM SPSS Statistics for Windows, v26 (Armonk, New York, NY, USA). Missing answers of specific questions was low in all surveys, $<5 \%$. Internal missing about asthma and respiratory symptoms was treated as a negative response while internal missing about exposures was treated as missing. The chi-square test was used to test for differences in proportions and the t-test for differences in means. Poisson regression analysis with physician-diagnosed asthma as outcome was utilised to estimate risk ratios (RR) with 95\% confidence intervals. The models were analysed both unadjusted and adjusted with age, sex, allergic rhino-conjunctivitis, family history of asthma, smoking habits and socioeconomic status included as covariates.

The cumulative incidence of physician-diagnosed asthma was estimated from two models of defining the population at risk. In model A, individuals with any of the following variables at baseline were excluded from the population at risk: physician-diagnosed asthma, ever having had asthma, asthma medication use, recurrent wheeze or attacks of SOB lasting 12 months. In model B, individuals were excluded from the population at risk if reporting having physician-diagnosed asthma at baseline. The cumulative incidence of asthma medication use and recurrent wheeze was also estimated by models A and B, and additionally by a third model $\mathrm{C}$, where the population at risk excluded those reporting asthma medication use at baseline when asthma medication use was analysed as the outcome variable, and where the population at risk excluded those reporting recurrent wheeze at baseline when recurrent wheeze was the outcome. As we did not have complete data on person-years, we used the cumulative incidence over the 10-year observation period in each cohort to estimate annual incidence rate by assuming the incidence to be constant. The estimated annual incidence rate was calculated as:

$$
\text { Incidence rate }=\frac{a}{(10 \times(b-(a / 2)))}
$$

where $a$ is the number of incident cases and $b$ the number of subjects in the population at risk at the start of the study, as also estimated in other studies [15, 18, 19].

\section{Results}

Baseline characteristics of the cohorts

In both cohorts the response rate was higher among women both at baseline and at the follow-ups (table 1). The mean age of the individuals was 44.6 years in the cohort recruited in 1996 and 47.7 years in the cohort recruited in 2006. Smoking was more common in the 1996 cohort than the 2006 cohort (27.4\% versus 19.3\%). Women reported significantly higher prevalence of attacks of SOB, allergic rhino-conjunctivitis and use of asthma medication than men in both cohorts (table 2).

\section{Incidence rates}

According to model A, the incidence rate of physician-diagnosed asthma for the period 1996 to 2006 was 2.4 per 1000 person-years (in total 108 new cases during the 10-year follow-up) with minor differences 


\begin{tabular}{|c|c|c|c|c|c|c|c|c|}
\hline & \multicolumn{4}{|c|}{ Cohort recruited in $1996^{\#}$} & \multicolumn{4}{|c|}{ Cohort recruited in $2006^{4}$} \\
\hline & Women & Men & All & p-value ${ }^{+}$ & Women & Men & All & p-value ${ }^{+}$ \\
\hline Age mean (SD) & $44.8(13.5)$ & $44.4(13.2)$ & $44.6(13.3)$ & 0.249 & $47.7(13.2)$ & $47.6(13.1)$ & $47.7(13.1)$ & 0.731 \\
\hline \multicolumn{9}{|l|}{ Smoking habits $\%$} \\
\hline Smoker & 27.7 & 23.9 & 25.8 & $<0.001$ & 20.5 & 14.2 & 17.5 & $<0.001$ \\
\hline Ex-smoker & 19.0 & 25.0 & 22.0 & & 23.4 & 23.9 & 23.6 & \\
\hline Nonsmoker & 53.3 & 51.1 & 52.2 & & 56.1 & 62.0 & 58.9 & \\
\hline Physician-diagnosed asthma \% & 8.6 & 9.1 & 8.8 & 0.461 & 12.1 & 9.9 & 11.1 & 0.016 \\
\hline Asthma medication \% & 11.3 & 9.6 & 10.5 & 0.029 & 13.5 & 10.8 & 12.2 & 0.005 \\
\hline Recurrent wheeze \% & 13.2 & 12.2 & 12.7 & 0.274 & 11.1 & 11.7 & 11.4 & 0.584 \\
\hline Attacks of shortness of breath \% & 15.4 & 12.5 & 13.9 & 0.002 & 14.1 & 11.9 & 14.3 & 0.026 \\
\hline Allergic rhino-conjunctivitis \% & 24.7 & 22.2 & 23.4 & 0.029 & 27.4 & 22.8 & 25.2 & $<0.001$ \\
\hline Family history of asthma \% & 24.6 & 18.6 & 21.6 & $<0.001$ & 25.5 & 19.8 & 22.8 & $<0.001$ \\
\hline \multicolumn{9}{|l|}{ Socioeconomic group \% } \\
\hline Professionals & 2.8 & 7.6 & 5.3 & $<0.001$ & 5.5 & 7.7 & 6.6 & $<0.001$ \\
\hline Non-manual workers & 43.7 & 27.8 & 35.6 & & 47.4 & 30.1 & 39.1 & \\
\hline Manual workers & 53.5 & 64.6 & 59.1 & & 47.1 & 62.1 & 54.3 & \\
\hline
\end{tabular}

between sex and age groups. Incidence of asthma medication use was higher among women than men (4.7 per 1000 person-years versus 3.4 per 1000 person-years, $\mathrm{p}=0.028$ ). The incidence rate of asthma for the period 2006 to 2016 was 2.6 per 1000 person-years (in total 93 new cases) and was higher among women than men (3.5 per 1000 person-years versus 1.7 per 1000 person-years, $\mathrm{p}=0.001$ ). The incidence of asthma medication use was also higher among women than men (5.7 per 1000 person-years versus 3.3 per 1000 person-years, $\mathrm{p}=0.001$ ) (table 3).

According to model B, the incidence of physician-diagnosed asthma for the period 1996 to 2006 was 4.4 per 1000 person-years (in total 225 new cases), and the incidence of asthma medication use was 7.4 per 1000 person-years. For the period 2006 to 2016 the corresponding incidence rates were 4.8 per 1000 person-years (in total 188 new cases) and 8.3 per 1000 person-years, respectively. These incidence estimates were all significantly higher among women (table 3).

According to model $\mathrm{C}$, where the population at risk only excluded those reporting the outcome variable at baseline, the incidence rates of asthma medication use and recurrent wheeze were between the estimations from models $\mathrm{A}$ and $\mathrm{B}$. The incidence of recurrent wheeze did not differ by sex in any model or observation period (table 3).

\section{Risk factors and respiratory symptoms of incident asthma}

In an adjusted Poisson regression analysis, allergic rhino-conjunctivitis was a significant risk factor for incident physician-diagnosed asthma, defined by model A, in both observation periods, with RR 2.62 (95\% CI 1.69-4.07) and RR 2.39 (95\% CI 1.48-3.87), respectively (table 4). Female sex was a significant risk factor in the observation period 2006 to 2016 (RR 1.99 (95\% CI 1.22-3.25)), but not from 1996 to 2006. Family history of asthma was a borderline risk factor for the period 1996 to 2006 (RR 1.50 (95\% CI 0.93-2.43)), but significant from 2006 to 2016 (RR 1.75 (95\% CI 1.05-2.90)). Ex-smoking was a borderline risk factor from 1996 to 2006.

The same analysis as above yielded a closely similar pattern also according to model B with family history of asthma, allergic rhino-conjunctivitis, female sex and ex-smoking as significant risk factors for incident physician-diagnosed asthma during the period 1996 to 2006. The same risk factors, except ex-smoking, were found for the period 2006 to 2016 (supplementary table S1).

Among individuals with adult-onset asthma in the cohort observed from 1996 to 2006, 70\% reported attacks of SOB in the last 12 months and $43 \%$ allergic rhino-conjunctivitis, and $83 \%$ used asthma medication at the follow-up in 2006. The corresponding figures for individuals with adult-onset asthma in the cohort observed from 2006 to 2016 were 65\%, 44\% and 80\%, respectively, and these figures did not differ significantly between incident cases in the two cohorts. 
TABLE 3 Incidence rate ( $\mathrm{n}$ per 1000 person-years) of different asthma variables by age group and sex and by use of different definitions of population at risk

\begin{tabular}{|c|c|c|c|c|c|c|c|c|c|c|c|c|c|c|c|}
\hline & \multirow[t]{3}{*}{ Outcome } & \multicolumn{6}{|c|}{ Cohort followed from 1996 to 2006} & \multirow[t]{3}{*}{ p-value ${ }^{\#}$} & \multicolumn{6}{|c|}{ Cohort followed from 2006 to 2016} & \multirow[t]{3}{*}{$p$-value } \\
\hline & & \multicolumn{3}{|c|}{ Age years } & \multicolumn{3}{|c|}{ Sex } & & \multicolumn{3}{|c|}{ Age years } & \multicolumn{3}{|c|}{ Sex } & \\
\hline & & $20-39$ & $40-59$ & $60-69$ & $\mathrm{~F}$ & M & All" & & $20-39$ & $40-59$ & $60-69$ & $\mathrm{~F}$ & M & All" & \\
\hline \multirow[t]{3}{*}{ Model A } & Physician-diagnosed asthma & 2.6 & 2.4 & 2.6 & 2.7 & 2.2 & 2.4 & 0.285 & 2.8 & 2.6 & 2.5 & 3.5 & 1.7 & 2.6 & 0.001 \\
\hline & Asthma medication use & 4.4 & 3.9 & 3.3 & 4.7 & 3.4 & 4.0 & 0.028 & 4.8 & 4.7 & 3.9 & 5.7 & 3.3 & 4.5 & 0.001 \\
\hline & Recurrent wheeze & 4.9 & 4.6 & 5.5 & 4.5 & 5.1 & 4.8 & 0.396 & 4.5 & 5.9 & 4.9 & 5.3 & 5.2 & 5.3 & 0.874 \\
\hline \multirow[t]{3}{*}{ Model B } & Physician-diagnosed asthma & 4.4 & 4.5 & 4.1 & 5.2 & 3.6 & 4.4 & 0.008 & 4.8 & 4.4 & 5.5 & 5.8 & 3.6 & 4.8 & 0.001 \\
\hline & Asthma medication use & 7.6 & 7.4 & 6.3 & 9,0 & 5.6 & 7.3 & $<0.001$ & 8.5 & 8.0 & 8.6 & 10.2 & 6.2 & 8.3 & $<0.001$ \\
\hline & Recurrent wheeze & 8.2 & 8.9 & 10.5 & 8.7 & 9.1 & 8.9 & 0.631 & 8.1 & 9.0 & 8.3 & 8.5 & 8.7 & 8.6 & 0.848 \\
\hline \multirow[t]{2}{*}{ Model C } & Asthma medication use & 6.2 & 5.7 & 5.2 & 7,0 & 4.6 & 5.8 & $<0.001$ & 6.6 & 6.8 & 5.9 & 8.3 & 4.7 & 6.5 & $<0.001$ \\
\hline & Recurrent wheeze & 6.0 & 6.3 & 7.9 & 6.3 & 6.6 & 6.5 & 0.698 & 7.8 & 7.1 & 6.2 & 7.4 & 6.8 & 7.1 & 0.473 \\
\hline
\end{tabular}

Model A: excluded from population at risk were those who at baseline reported any of physician-diagnosed asthma, ever-asthma, current use of asthma medicine and recurrent wheeze. Model B: excluded from population at risk were those who reported physician-diagnosed asthma at baseline. Model C: excluded from population at risk were those who at baseline reported the outcome variable. F: females; M: males. ": p-value for differences in cumulative incidence by sex, p-values in bold indicate statistical significance; ๆ: no statistical difference by study period of any of the outcome variables was found. 
TABLE 4 Risk factors for incident adult-onset physician-diagnosed asthma defined by model A

\begin{tabular}{|c|c|c|c|c|c|c|c|c|c|}
\hline \multirow[t]{3}{*}{ Independent variables } & \multirow[t]{3}{*}{ Category } & \multicolumn{4}{|c|}{ Cohort followed from 1996 to 2006} & \multicolumn{4}{|c|}{ Cohort followed from 2006 to 2016} \\
\hline & & \multicolumn{2}{|c|}{ Unadjusted } & \multicolumn{2}{|c|}{ Adjusted } & \multicolumn{2}{|c|}{ Unadjusted } & \multicolumn{2}{|c|}{ Adjusted } \\
\hline & & $\mathrm{RR}$ & $(95 \% \mathrm{Cl})$ & $\mathrm{RR}$ & $(95 \% \mathrm{Cl})$ & RR & $(95 \% \mathrm{Cl})$ & RR & $(95 \% \mathrm{Cl})$ \\
\hline \multirow[t]{2}{*}{ Sex } & Men & 1 & & 1 & & 1 & & 1 & \\
\hline & Women & 1.23 & $(0.84-1.79)$ & 1.18 & $(0.77-1.79)$ & 2.07 & $(1.34-3.21)$ & 1.99 & $(1.22-3.25)$ \\
\hline Family history of asthma & No & 1 & & 1 & & 1 & & 1 & \\
\hline Allergic rhino-conjunctivitis & Yes & 2.47 & $(1.65-3.69)$ & 2.62 & $(1.69-4.07)$ & 2.42 & $(1.58-3.71)$ & 2.39 & $(1.48-3.87)$ \\
\hline \multirow[t]{3}{*}{ Smoking habits } & Nonsmokers & 1 & & 1 & & 1 & & 1 & \\
\hline & Ex-smokers & 1.67 & $(1.06-2.62)$ & 1.62 & $(0.99-2.67)$ & 0.87 & $(0.58-1.58)$ & 1.01 & $(0.59-1.75)$ \\
\hline & Smokers & 1.42 & $(0.89-2.26)$ & 1.38 & $(0.83-2.29)$ & 0.79 & $(0.42-1.47)$ & 0.89 & $(0.46-1.69)$ \\
\hline \multirow[t]{2}{*}{ Socioeconomic group } & Professionals & 1 & & 1 & & 1 & & 1 & \\
\hline & Non-manual workers & 1.46 & $(0.45-4.80)$ & 1.32 & $(0.40-4.37)$ & 0.88 & $(0.37-2.12)$ & 0.76 & $(0.31-1.89)$ \\
\hline
\end{tabular}

Data are presented as unadjusted and adjusted RR $(95 \% \mathrm{Cl})$ from Poisson regression models. Model A: excluded from population at risk were those who at baseline reported any of physician-diagnosed asthma, ever-asthma, current use of asthma medicine and recurrent wheeze. The adjusted regression models included incident physician-diagnosed asthma as outcome, and all variables presented in the table as independent variables. Bold values indicate $p<0.05$.

\section{Discussion}

The main finding of these prospective population-based cohort studies was that the incidence of adult-onset asthma in northern Sweden was stable from 1996 to 2016, and at a similar level as that from 1986 to 1996 [12, 15]. Thus, the reported increase in asthma prevalence during recent decades is not explained by an increase in adult-onset asthma incidence but by the stable and relatively high incidence (2-3 per 1000 person-years). The incidence was consistently higher among women than men. In analyses adjusted for covariates, allergic rhino-conjunctivitis was the main risk factor for adult-onset asthma in both periods.

To the best of our knowledge we are the first to report about trends in adult-onset asthma incidence over several decades. A review article including incidence studies from the 1950s to 1990s indicated an increase in incidence rate with time; however, the methods varied substantially between the included studies [28]. Three longitudinal population-based studies performed in Sweden and neighbouring countries during the 1980s and 1990s with almost identical methods found an incidence rate of 2-3 per 1000 person-years [15, 16, 18]. Our results, 2.4 per 1000 person-years from 1996 to 2006 and 2.6 per 1000 person-years from 2006 to 2016, are in line with these studies, including the previous study in our region (figure 1) [15], and indicate a continuing stable trend in incidence rate in Sweden as a whole. However, an incidence rate of 2-3 per 1000 person-years in combination with low remission of asthma in adulthood $[6,7,18]$ and similar mortality among adults with asthma as in the general population means about $1 \%$ unit increase in prevalence every 10 years and thus contribute to the slowly increasing prevalence of asthma among adults.

Only a limited number of incidence studies of adult-onset asthma are based on prospective longitudinal population-based studies [12-21, 23]. These studies show considerable variation in results, 0.7-6 per 1000 person-years, due to variations in the study design [11, 13, 14, 25] and the definitions of the outcome and the population at risk $[12,14-16,18]$. Studies ending up with high incidence rates have often not excluded individuals with symptoms common in asthma from the population at risk. To enable valid comparisons between different studies it is paramount to use identical methods.

Symptoms of asthma may occur several years before a diagnosis of asthma is made, and these symptoms may reflect undiagnosed asthma in the population, which is why the incidence rate may be overestimated. To reduce this bias it is reasonable to also exclude subjects reporting symptoms of asthma from the population at risk. When comparing different populations at risk (model A versus B) we found that the difference in incidence rate of physician-diagnosed asthma between the two models was much smaller in the two current cohorts under study compared with the study from the 1980s, which was performed with almost identical methods in the same area (figure 1). When using model B (not correcting for possible under-diagnosis), the incidence of physician-diagnosed asthma was 4.4-4-8 per 1000 person-years in the current cohorts, while it was 8 per 1000 person-years in the 1980s cohort [12]. This may reflect a decrease 


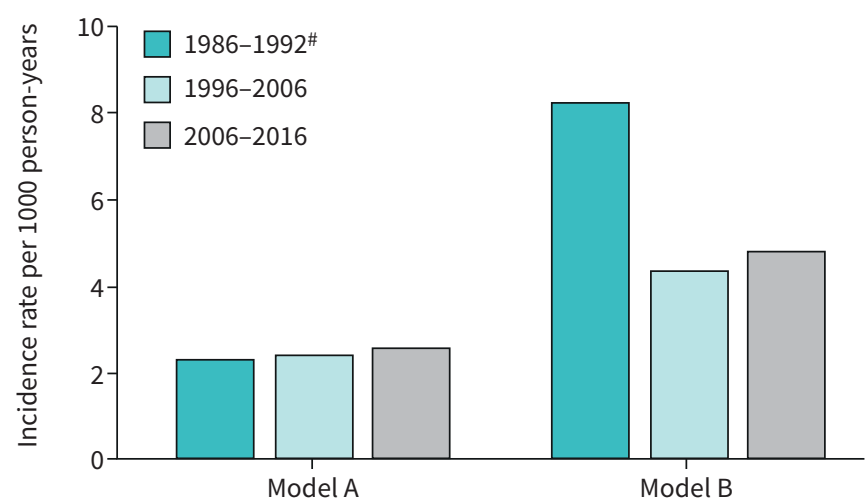

FIGURE 1 Incidence rate of physician-diagnosed asthma over three decades, from 1986 to 2016, estimated by two different models of defining population at risk. Model A: excluded from population at risk were those who at baseline reported physician-diagnosed asthma, ever-asthma, current use of asthma medicine and recurrent wheeze. Model B: excluded from population at risk were those who reported physician-diagnosed asthma at baseline. " : Rönmark et al. [12].

in under-diagnosis of asthma since the 1980s, probably due to changed diagnostic practice and higher awareness of asthma in healthcare and society today [2, 26]. However, at the follow-up of our two current cohorts in 2006 and 2016, individuals with incident asthma reported similar prevalence of symptoms of asthma and use of asthma medication. This indicates a similar disease burden among individuals with adult-onset asthma today as 10 years ago, which in part contradicts the suggested diagnostic drift regarding asthma in healthcare. On the other hand, the major change may have occurred before the millennium shift as a consequence of a Swedish national programme focusing on asthma during 1995, and perhaps even be related to the start of the OLIN-research programme in the study area in 1986, resulting in increased awareness of asthma in the society. Still, the higher incidence rate of use of asthma medication compared with asthma diagnosis may indicate some under-diagnosis of asthma also today. Nevertheless, asthma medication is also used in other respiratory diseases, such as bronchitis and COPD, which probably contributes to the high incidence.

In line with previous studies, we found that women had a higher incidence of adult-onset asthma compared with men (figure 2) [12-24, 29, 30]. This is in contrast to children, where the incidence is higher among boys than girls $[8,9,11,22]$. The reason for the sex differences is unclear but may be related to hormonal status [29]. The obese-asthma phenotype, often found in adult-onset asthma among women [5, 29], may be mediated by interactions between sex hormones and systemic inflammation [31]. Female sex has also been

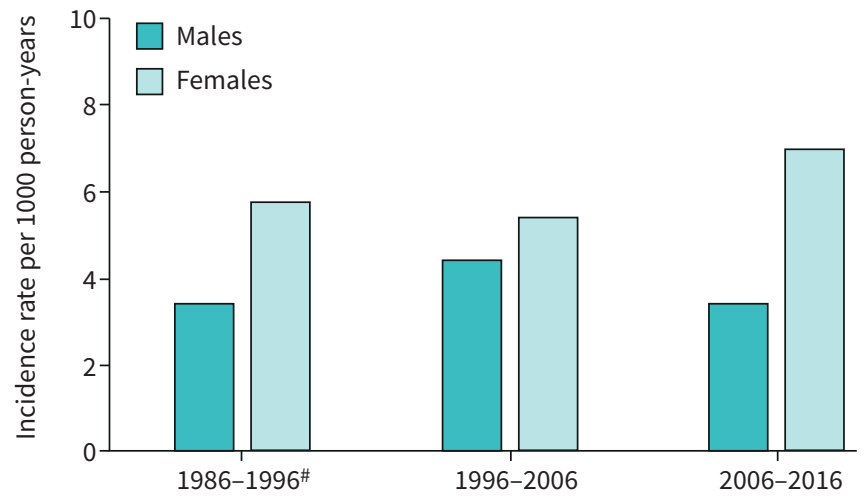

FIGURE 2 Incidence rate of physician-diagnosed asthma by sex for three decades, from 1986 to 2016. Incident cases were defined by model $\mathrm{A}$ in all cohorts. Model A: excluded from population at risk were those who at baseline reported physician-diagnosed asthma, ever-asthma, current use of asthma medicine and recurrent wheeze. ": LUNDBäck et al. [15]. 
reported to be a predictor for persistent asthma from childhood to adulthood [32, 33], which is why it seems that the increasing prevalence of asthma among adults is mainly driven by women, i.e. by lower remission rate of childhood asthma and higher incidence rate of adult-onset asthma in women than in men.

Allergic rhino-conjunctivitis is a well-known risk factor for asthma $[4,17,19,21]$ and is a reasonable proxy for allergic sensitisation, at least among younger and middle-aged adults [21]. In the current study it was the strongest and most stable risk factor for asthma, which further strengthens the causality of the association. Several previous studies have found smoking or ex-smoking associated with incidence of asthma [4, 10, 12, $15,19,23]$. In the current study we found that, from 2006, neither smoking nor ex-smoking remained as risk factors for incident asthma among adults. This change is probably a result of the considerable decrease in smoking that has occurred during the last decades in Sweden $[2,26]$. Not only has the prevalence of smoking decreased, but also the number of cigarettes smoked per day has been reduced [2]. In contrast to previous studies that have reported several markers for low socioeconomic status to be associated with incident asthma [34-36], we did not find any consistent associations with socioeconomic status based on occupation. However, though not significant, the RR for manual work was 1.75 in the 1996 cohort, while the RR was close to 1 in the most recent cohort. This may be due to improvements in the working environment, but may also be due to lack of power in our study, not allowing more detailed occupational classifications.

Several strengths support the validity of the results. First, we used two large population-based cohorts within the same age-span and geographical area, and both cohorts were followed for 10 years. Second, the response rate was high in both cohorts, both at recruitment and follow-up. Third, for high comparability with previous studies $[12,15,18]$ we used identical methods in the calculations of incidence, and these were based on the same validated questionnaire [27]. Furthermore, the prospective design is, compared with retrospective studies, less associated with recall bias [11, 25]. Although the internal validity can be regarded as high, the external validity is unclear due to the lack of studies of trends in asthma incidence. A limitation worth noting is that despite the large sample sizes of the cohorts and the relatively long follow-up, the study lacks power for subgroup analyses. The studies were based on questionnaire data, which may have introduced some bias, and is why we cannot rule out that some of those diagnosed as having asthma in reality had COPD. However, the incidence was similar across all age groups. Another weakness is the limited information about risk factors such as body mass index and education level, factors that have been associated with adult-onset asthma [4, 5, 29, 34].

\section{Conclusion}

Based on identical methods, the incidence of adult-onset asthma was stable from 1996 to 2016 and has remained at an almost identical level since the 1980s. The observed high incidence in parallel with low remission in adulthood contribute to the ongoing increase in prevalence of asthma among adults. As previously found, the incidence was higher among women than men and allergic rhino-conjunctivitis was the main risk factor.

Acknowledgements: The research staff within the OLIN studies are acknowledged for excellent data collection throughout the years.

Conflict of interest: P. Räisänen has nothing to disclose. H. Backman reports personal fees from Boehringer Ingelheim and AstraZeneca outside the submitted work. L. Hedman has nothing to disclose. M. Andersson has nothing to disclose. C. Stridsman reports personal fees from AstraZeneca, Boehringer Ingelheim and Novartis outside the submitted work. H. Kankaanranta reports fees for lectures and consulting, and costs for attending an international congress from AstraZeneca, Boehringer Ingelheim and Orion Pharma; fees for consulting and lectures from Chiesi Pharma AB, Novartis and GlaxoSmithKline; fees for lectures from Mundipharma; and fees for consulting from SanofiGenzyme, all outside the submitted work. P. Ilmarinen reports a fee for a lecture from and has been an employee of GlaxoSmithKline since March 2021, and reports fees for lectures from Mundipharma and AstraZeneca, and a fee for a lecture and for preparing presentation material from Novartis, outside the submitted work. H. Andersen has nothing to disclose. P. Piirilä has nothing to disclose. A. Lindberg reports personal fees for lectures and an advisory board from Boehringer Ingelheim, personal fees for advisory boards from AstraZeneca and GlaxoSmithKline, and personal fees for lectures from Novartis, outside the submitted work. B. Lundbäck reports personal fees for lecturing and advisory meeting participation from Novartis, personal fees for advisory meeting participation from Sanofi, and a grant for a study on study on respiratory epidemiology from AstraZeneca, outside the submitted work. R. Rönmark reports grants from the Swedish Heart and Lung fundation, the Swedish Asthma and Allergy Foundation, Norrbotten county council, and ALF (a regional agreement between Umeå University, Västerbotten county council and Norrbotten county council), during the conduct of the study; and lecture fees from AstraZeneca, outside the submitted work. 
Support statement: The study was funded by grants from The Swedish Heart and Lung Foundation; ALF, a regional agreement between Umeå University and Västerbotten and Norrbotten County Council; The Swedish Asthma-Allergy Foundation; Visare Norr; and Norrbotten County Council. Funding information for this article has been deposited with the Crossref Funder Registry.

\section{References}

1 Sears M. Trends in the prevalence of asthma. Chest 2014; 145: 219-225.

2 Backman H, Räisanen P, Hedman L, et al. Increased prevalence of allergic asthma from 1996 to 2006 and further to 2016: results from three population surveys. Clin Exp Allergy 2017; 47: 1426-1435.

3 Eguiluz-Gracia I, Mathioudakis AG, Bartel S, et al. The need for clean air: the way air pollution and climate change affect allergic rhinitis and asthma. Allergy 2020; 75: 2170-2184.

4 Rönmark E, Andersson C, Nyström L, et al. Obesity increases the risk of incident asthma among adults. Eur Respir J 2005; 25: 282-288.

5 Beuther DA, Sutherland ER. Overweight, obesity, and incident asthma: a meta-analysis of prospective epidemiologic studies. Am J Respir Crit Care Med 2007; 175: 661-666.

6 Vonk JM, Nieuwenhuis MAE, Dijk FN, et al. Novel genes and insights in complete asthma remission: a genome-wide association study on clinical and complete asthma remission. Clin Exp Allergy 2018; 48: 1286-1296.

7 Almqvist L, Rönmark E, Stridsman C, et al. Remission of adult-onset asthma is rare: a 15-year follow-up study. ERJ Open Res 2020; 6: 00620-2020.

8 Dharmage SC, Perret JL, Custovic A. Epidemiology of asthma in children and adults. Front Pediatr 2019; 7: 246.

9 Stern DA, Morgan WJ, Halonen M, et al. Wheezing and bronchial hyper-responsiveness in early childhood as predictors of newly diagnosed asthma in early adulthood: a longitudinal birth-cohort study. Lancet 2008; 372 1058-1064.

10 Norrman E, Nyström L, Jönsson E, et al. Prevalence and incidence of asthma and rhinoconjunctivitis in Swedish teenagers. Allergy 1998; 53: 28-35.

11 Strachan DP, Butland BK, Anderson HR. Incidence and prognosis of asthma and wheezing illness from early childhood to age 33 in a national British cohort. BMJ 1996; 312: 1195-1199.

12 Rönmark E, Lundbäck B, Jönsson E, et al. Incidence of asthma in adults: report from the Obstructive Lung Disease in Northern Sweden Study. Allergy 1997; 52: 1071-1078.

13 Vesterinen E, Kaprio J, Koskenvuo M. Prospective study of asthma in relation to smoking habits among 14,729 adults. Thorax 1988; 43: 534-539.

14 Basagana X, Sunyer J, Zock JP, et al. Incidence of asthma and its determinants among adults in Spain. Am J Respir Crit Care Med 2001; 164: 1133-1137.

15 Lundbäck B, Rönmark E, Jönsson E, et al. Incidence of physician-diagnosed asthma in adults: a real incidence or a result of increased awareness? Report from the Obstructive Lung Disease in Northern Sweden Studies. Respir Med 2001; 95: 685-692.

16 Toren $\mathrm{K}$, Gislason T, Omenaas E, et al. A prospective study of asthma incidence and its predictors: the RHINE study. Eur Respir J 2004; 24: 942-946.

17 Thomsen SF, Ulrik CS, Kyvik KO, et al. The incidence of asthma in young adults. Chest 2005; 127: 1928-1934.

18 Ekerljung L, Rönmark E, Larsson K, et al. No further increase of incidence of asthma: incidence, remission and relapse of adult asthma in Sweden. Respir Med 2008; 102: 1730-1736.

19 Pallasaho P, Juusela M, Lindqvist A, et al. Allergic rhinoconjunctivitis doubles the risk for incident asthma: results from a population study in Helsinki, Finland. Respir Med 2011; 105: 1449-1456.

20 Winer RA, Qin X, Harrington T, et al. Asthma incidence among children and adults: findings from the Behavioral Risk Factor Surveillance system asthma call-back survey -United States, 2006-2008. J Asthma 2012; 49: 16-22.

21 Gallmeier K, Becker E, Kirsten A, et al. Prediction of new-onset asthma and nasal allergy by skin prick test and RAST in a cohort of adults. Eur Respir J 2014; 43: 92-102.

22 Wu TJ, Wu CF, Lee YL, et al. Asthma incidence, remission, relapse and persistence: a population-based study in southern Taiwan. Respir Res 2014; 15: 135-139.

23 Verlato G, Nguyen G, Marchetti P, et al. Smoking and new-onset asthma in a prospective study on Italian adults. Int Arch Allergy Immunol 2016; 170: 149-157.

24 Pakkasela J, Ilmarinen P, Honkamäki J, et al. Age-specific incidence of allergic and non-allergic asthma. BMC Pulm Med 2020; 20: 9.

25 Brogger J, Eagan T, Eide GE, et al. Bias in retrospective studies of trends in asthma incidence. Eur Respir J 2004; 23: 281-286.

26 Borna $\mathrm{E}, \mathrm{Nwaru} \mathrm{BI}, \mathrm{Bjerg} \mathrm{A}$, et al. Changes in the prevalence of asthma and respiratory symptoms in western Sweden between 2008 and 2016. Allergy 2019; 74: 1703-1715. 
27 Lundbäck B, Stjernberg N, Rosenhall L, et al. Methacholine reactivity and asthma. Report from the Northern Sweden Obstructive Lung Disease Project. Allergy 1993; 48: 117-124.

28 Eagan TML, Brøgger JC, Eide GE, et al. The incidence of adult asthma: a review. Int J Tuberc Lung Dis 2005; 9: 603-612.

29 Sood A, Qualls C, Schuyler M, et al. Adult-onset asthma becomes the dominant phenotype among women by age 40 years. Ann Am Thorac Soc 2013; 10: 188-197.

30 de Marco R, Locatelli F, Sunyer J, et al. Differences in incidence of reported asthma related to age in men and women. A retrospective analysis of the data of the European Respiratory Health Survey. Am J Respir Crit Care Med. 2000; 62: 68-74.

31 Scott HA, Gibson PG, Garg ML, et al. Sex hormones and systemic inflammation are modulators of the obese-asthma phenotype. Allergy 2016; 71: 1037-1047.

32 Andersson M, Hedman L, Bjerg A, et al. Remission and persistence of asthma followed from 7 to 19 years of age. Pediatrics 2013; 132: 435.

33 Sears MR, Greene JM, Willan AR, et al. A longitudinal, population-based, cohort study of childhood asthma followed to adulthood. N Engl J Med 2003; 349: 1414-1422.

34 Eagan TM, Gulsvik A, Eide GE, et al. The effect of educational level on the incidence of asthma and respiratory symptoms. Respir Med 2004; 98: 730-736.

35 Hedlund U, Eriksson K, Rönmark E. Socio-economic status is related to incidence of asthma and respiratory symptoms in adults. Eur Respir J 2006; 28: 303-310.

36 Maio S, Baldacci S, Carrozzi L, et al. 18-yr cumulative incidence of respiratory/allergic symptoms/diseases and risk factors in the Pisa epidemiological study. Respir Med 2019; 158: 33-41. 